\title{
Ser partidario de las víctimas
}

T. Micilalil McNulity, SJ

Depto. de Filosofía

Marquette University

Una versión abreviada de este trabajo fue presentada en la conferencia "Pobreza, Corrupción y Derechos Humanos: Ética Ciudadana y Función Pública", Sexta Conferencia Internacional de Ética y Desarrollo, Instituto Zamorano, Honduras, celebrada del 19 al 22 de junio de 2002 y organizada por la Asociación Internacional de Ética del Desarrollo (IDEA).

Al menos desde el siglo XVIII, la filosofía ha dado por descontado que todas las voces tienen el mismo derecho a nuestra atención. Una sociedad pluralista tiene que mantener la neutralidad, permitiendo intereses competentes a negociar su lugar por medio del diálogo y argumento. Quisiera sugerir que esta posición sea insostenible, porque excluye las voces de los pobres y marginados, las víctimas de fuerzas económicas globales que infligen dolencia terrible sobre ellos sin posibilidad de reparación. Gustavo Gutiérrez comenta en algún lugar que, mientras que el interlocutor de la especulación filosófica y teológica moderna tradicionalmente ha sido la Ilustración, el interlocutor del Tercer Mundo ha sido la Muerte. La reflexión moral del Primer Mundo ha sido y sigue siendo una extensión de las presuposiciones de este último. 
El título de esta conferencia se deriva de la novela de Albert Camus, La peste, en un discurso que pronuncia cl doctor Tarrou:

"Si cada uno lleva en sí mismo la peste, porque nadie, nadie en el mundo está indemne de ella. Y sé que hay que vigilarse a sí mismo sin cesar para no ser arrastrado en un minuto de distracción a respirar junto a la cara de otro y pegarle la infección... El hombre íntegro, el que no infecta a casi nadie es el que tiene el menor número posible de distracciones. iY hace falta tal voluntad y tal tensión para no distraerse jamás! Sé únicamente que hay en este mundo plagas y víctimas y que hay que negarse tanto como le sea a uno posible a estar con las plagas... [T] odas las desgracias de los hombres provienen de no hablar claro. Entonces he tomado el partido de hablar y obrar claramente, para ponerme en buen camino. Así que afirmo que hay plagas y víctimas, y nada más. Por esto decido ponerme del lado de las víctimas para evitar estragos".'

Espero que la relevancia de la decisión de Tarrou se haga claro cuando llegamos al fin de nuestra discusión.

La tolerancia que caracteriza el discurso político, económico y moral del Primer Mundo parece asegurar la inclusividad. Sin embargo, de hecho, por dar a todas las voces igual importancia, margina efectivamente a los pobres, que están incapaces de entrar en la conversación. Roberto Goizueta ofrece cuatro razones para esto:

1) Los juicios éticos se relegan a la privacidad de la conciencia individual, y excluyen, por lo tanto, toda discusión pública sobre un bien comuin;

2) El relativismo radical que resulta de la privatización de los juicios éticos evita que sea posible el adjudicar entre reclamos éticos competentes.

3) La imposibilidad de adjudicar entre reclamos competentes evita, en su turno, la posibilidad de hacer una opción preferencial por los pobres.

4) Por eso se "oye" la voz de la persona marginada tan sólo como una entre muchas otras, incapaz de hacer algún reclamo normativo, verbigracia, en nombre de la justicia o el bien común.'

Goizueta continúa: "Si el 'bien común' y la 'solidaridad' no han de quedarse en meras abstracciones, con todo, tienen que entenderse a la 
luz de la opción preferencial por los pobres. Lo que les da a los marginados un mejor discernimiento sobre el bien común no son sus calidades morales, sino su sitio social, su lugar estratégico."

Es una trivialidad de la ética que el comportamiento debe determinar la manera de que una persona es tratada por los demás. Los pobres y marginados, con todo, son las víctimas de fuerzas históricas sobre las cuales no tienen control alguno. En este sentido son los "ausentes de la historia." El ser víctima lleva consigo la implicación de ser inocente en algún sentido apropiado de ese término. El diccionario añade que muchas veces las víctimas sufren mucho a causa del tratamiento cruel y opresivo. El espectador que es ultimado por una bala extraviada al subir al metro es inocente en este sentido: hay una desconexión moral entre la desgracia y cualquier acción de la víctima. En este caso, no hay ninguna razón para esperar que subir a una estación de metro pondría en peligro la vida de cualquiera. Se pueden multiplicar los ejemplos de este tipo: las personas que mueren a causa de un relámpago, pestilencias contagiosas, terremotos y cosas similares. Necesitamos, con todo, mirar más allá de los desastres naturales y encuentros casuales con el mal.

Las fuerzas sociales, políticas y económicas que forman el contexto actual de la interacción humana, especialmente al nivel internacional, son parcialmente el resultado de la adopción de un punto de vista mundial particular. Quisiera enfocar este discurso en las víctimas a quienes aludí antes, las víctimas de fuerzas sociales y económicas que tantas veces impactan negativamente en las vidas de los seres humanos. Estos casos son significantes, tanto por la severidad de la victimización, como por la falta aparente de un agente intencional. Permíteme presentar un ejemplo:

Supóngase que el área mayor de terreno de un pueblito fuera la propiedad del descendiente de una familia que había tenido las escrituras del terreno por tantas generaciones en el pasado como podía recordarse. Según los estándares absolutos, este campesino no era rico en modo alguno, pero su terreno era el más rico de la región pequeña que constituía el universo de los habitantes del pueblito. Cultivaba, como habian hecho su padre y abuelo, principalmente los frijoles negros que son la fuente básica de proteínas de la dieta regional. Su cosecha constituía usualmente más o me- 
nos la cuarta parte de los frijoles negros que eran vendidos en el pueblito. Casi todas las familias cultivaban una parte de lo que necesitaban, y los seis hombres que el terrateniente empleaba durante las estaciones que necesitaban trabajo adicional tenían los únicos puestos asalariados en el pueblito- todos los demás sólo trabajaban sus propios terrenos pequeños. Un día, un hombre de la capital le ofreció a este campesino un contrato que le garantizaba, no sólo pagos anuales por arrendar durante diez años su terreno, sino también un sueldo (no obstante, como estaba el tiempo, y por eso la cosecha- un aumento de su seguridad financiera) por dirigir un tipo nuevo de producción en su terreno. El contrato requería que cultivara flores para exportación y también le ofrecía la oportunidad, que se recomendaba fuertemente, de comprar por la compañía, con pagos en abonos, el equipo que posibilitaría que necesitara emplear solamente dos hombres. El mismo contrato se ofreció la mayoría de los terratenientes grandes en la región a la que pertenecía el pueblito, quienes lo aceptaron.

Luego, con la reducción aguda de la oferta, el precio de los frijoles negros subió muy alto. Algunas personas podían cultivar todo lo que necesitaban (en los años del buen tiempo) en su terreno propio, pero las familias que necesitaban suplir sus propias cosechas con compras, tenían que reducir su consumo. En particular, los niños de las cuatro familias encabezadas por los trabajadores que perdían su empleo ocasional sufrían de desnutrición severa, puesto que los padres habían trabajado originalmente como obreros, solamente porque su terreno propio era demasiado pobre o demasiado pequeño para dar comida a sus familias. ${ }^{+}$

Este cuento ilustra un par de puntos importantes: 1) Las víctimas de la opresión social y económica son muchas veces los niños; 2) Es extremamente difícil en tales escenarios atribuir culpas. Nada indica en el cuento que alguien esté tratando premeditadamente de explotar o hacer daño a algún otro. De hecho, tenemos la imagen de una persona prudente que está aprovechando una oportunidad ofrecida para transformar un recurso poseído legítimamente en una fuente mayor de seguridad económica. Tampoco puede ser reprendido el agente de la capital. Él no obligaba a nadie y parece que actuaba de buena fe como intermediario entre el terrateniente y la empresa. 
La ideología del libre comercio y la globalización no tiene espacio para el grito de la víctima. En el cuento sería posible argüir que la causa verdadera de la miseria de los niños desnutridos en el pueblito sea el apetito de flores baratas, sin necesidad de darse cuenta de la estación, de parte de consumidores del Primer Mundo. Pero hay una desconexión psicológica entre un deseo aparentemente inocente por un poco de color alrededor de la casa entre gente que tiene los recursos económicos para gratificarlo, y las consecuencias remotas por víctimas inocentes medio mundo lejos. Hay también una desconexión moral entre la trivialidad del deseo satisfecho y las consecuencias extremas [la pobrezá y la desnutrición] para las familias campesinas que están afectadas negativamente.

¿Qué más da? Ten paciencia, se dice. Una marea que está subiendo llevanta todas las barcas. Eventualmente va a mejorar la vida aun para ellos que están debajo del montón económico. Sólo un mercado sin limitaciones y el libre comercio global tienen la posibilidad de derrotar la pobreza. Desdichadamente, la evidencia, hasta la fecha, no se divisa. Se indica que están empeorando las cosas: el Informe sobre Desarrollo Humano de la ONU de 1999 muestra una brecha de ingresos entre el quinto del mundo más rico y el quinto más pobre de 74 a 1, arriba de 30 a 1 en 1960. Todos estamos conscientes de las estadísticas: Según la FAO, cerca de 40,000 niños mueren diariamente por desnutrición. El Consejo de Desarrollo Mundial describe la distribución de los bienes en términos de un vaso para champagne: el $10 \%$ más alto de la población mundial controla más riquezas que el $90 \%$ más bajo. Tampoco es el caso que el ingreso es el único problema. La ideología neoliberal favorece la conversión de la agricultura tradicional (como es típica, por ejemplo, en Chiapas, México) en un monocultivo que puede mecanizarse de forma más fácil, e integrado en una economía global. Como consecuencia, la población indígena sufre una transformación en obreros asalariados, trabajando a cambio de un salario, las más de las veces, escaso. Estamos presenciando, en las palabras de Dean Brackley, S.J., la "globalización del Sur del Bronx."

Se podría argüir que, dada la conveniencia de las instituciones sociales de la democracia y el libre comercio, la desigualdad de la distribución económica no sólo es moral, sino también inevitable." ¿Qué tiene de malo permitir que las personas talentosas trabajen en función de sus propios intereses, aprovechándose de las circunstancias que se 
les presentan, a condición de que no interfieran en la libertad de otros individuos que quieren hacer lo mismo? Pero el asunto es que el trabajo industrioso y la perseverancia, aun en el caso de personas muy talentosas, no tendrá éxito sin las circunstancias sociales, económicas y históricas favorables. Un campesino joven de Chalatenango, El Salvador, tiene poca esperanza de mejorar sus circunstancias, a menos que pueda de algún modo emigrar al Norte, legalmente, o (más probable) de forma ilegal.

Hay supuestos profundos sobre la naturaleza humana y la ética dentro de este punto de vista, los cuales no podemos tratar aquí. Pero hay un problema filosófico que no puede dejarse a un lado. Ignacio Ellacuría, S.J., el martirizado rector de la Universidad Centroamericana en El Salvador, argumentaba que el estilo de vida del Primer Mundo era, no sólo el resultado inevitable del desarrollo económico natural. Era, desde su perspectiva, positivamente inmoral, por la razón muy kantiana de que no es universalizable.' La tierra, simplemente, no posee los recursos necesarios para permitir que todos (o la mayoría de la gente, tan siquiera) gocen del nivel de vida del Primer Mundo. Sólo es necesario imaginar el espectáculo de 1.3 mil millones de chinos manejando vehículos deportivos para darse cuenta del impacto de esta verdad.

Las cosas, con todo, son mucho más peores: No sólo no es universalizable el nivel de vida del Primer Mundo, sino que todavía no existe un campo común para el diálogo. Las democracias del Primer Mundo controlan los medios de expresión y establecen las reglas del diálogo. "Las comunidades reales, estables y duraderas de comunicación”, según Antonio González, S.J., "junto con todas sus instituciones democráticas, son justamente una parte constitutiva de esa forma de vida occidental que no es universalizable." En realidad, las víctimas no tienen voz. El incluir a los oprimidos en la comunidad de diálogo lleva el mismo peligro para el planeta que tratar de elevar a los pobres al nivel de consumo del Norte acaudalado. Los habitantes del Primer Mundo no tienen ni la menor idea de la comodidad de sus vidas. No reconocen la inmensa inversión en la infraestructura (la electricidad, el teléfono, el agua, la calefacción, las carreteras, el petróleo, etc.) de que dependen pero que les queda invisible. Es por esta razón que hablar de elecciones "libres" provoca una reacción de apatía y cinismo entre las poblaciones de muchas partes del mundo. Las elecciones libres no

\section{8}


pueden separarse del conjunto del sistema entrelazado de recursos, las posibilidades de comunicación y las tradiciones que las democracias del occidente dan por supuestas, pero que están, en gran parte, ausentes del Sur empobrecido.

¿Cuáles son las consecuencias de esta situación? Richard Rorty esboza el problema con claridad brutal:

He estado proponiendo un argumento filosófico que depende de tres premisas. La primera, es que la pregunta primordial de la filosofía no es "¿Qué somos nosotros?", sino: “¿Quiénes somos nosotros?" La segunda es que "¿Quiénes somos nosotros?" quiere decir: "¿A qué comunidad de confianza recíproca pertenecemos?" La tercera es que la confianza recíproca depende tanto de la factibilidad, como de la buena voluntad. La conclusión que saco de estas premisas es que el pensar en otras personas como parte del mismo "nosotros" depende no sólo de la voluntad a ayudar a esas personas sino también de la creencia que se puede ayudarlas. En particular, responder a la pregunta "¿Quiénes somos nosotros?", afirmando: "Somos miembros de una comunidad moral que abarca la especie humana", depende de la habilidad a creer que podemos evitar el triage económico."

Si los habitantes del mundo desarrollado no pueden evitar el triage económico, con todo, están confrontados por la necesidad de tratar a los pobres como "excedentes a sus requisitos morales, incapaces de desempeñar un papel en su vida moral. Los ricos y afortunados se vuelven incapaces de pensar de los pobres y desafortunados como consocios de la raza humana, como parte del mismo 'nosotros'."10

¿Hay otra posibilidad? Tal vez Rorty ha invertido el problema. Su reclamo es que sólo podemos compartir la comunidad moral con los que estamos capaces de ayudar. Tal vez sea el revés: sólo podemos ayudar a los con quienes compartimos la comunidad moral. La cuestión no es tanto nuestra obligación moral a ayudar como el reconocimiento del otro como consocio, como aun Aristóteles notó en la Ética nicomaquea. En un desvío curioso de su punto de vista clasista y machista, dijo: "Se puede también observar viajando a países lejanos los sentimientos de reconocimiento y afiliación que acoplan todo ser humano a todo otro." [1155 a 21-22]" No queda en los principios abstractos sino en la interacción humana que encontramos las conexiones que constituyen la comunidad práctica. Enten- 
deremos la comunidad mejor si la vemos como un grupo de personas atadas unas a otras por un tipo de compasión. Los filósofos han intentado por mucho tiempo de articular el tipo de igualdad que presupone la teoría democrática, que aparentemente no está basada en las calidades poseídas por los individuos. Henri Nouwen lo formula en la siguiente manera:

La compasión se manifiesta en la solidaridad, la consciencia profunda de ser parte de la humanidad, la sabiduría existencial de la unidad de la raza humana, el conocimiento íntimo que toda la gente, separada como esté por el tiempo y el espacio, está unida por la misma condición humana. La solidaridad es más — mucho másque la afirmación intelectual de la humanidad compartida; es la experiencia palpada profundamente de la identidad humana. ${ }^{12}$

La compasión, entonces, es la experiencia fundamental de mí mismo como uno-entre-otros, el reconocimiento de que todos los demás son exactamente como yo.

¿Cómo se manifiesta la solidaridad? Simon Weil la describe (paradójicamente) como el reconocimiento de la impersonalidad de la justicia: "Todos los seres humanos son absolutamente idénticos en cuanto a se puede pensar de ellos como consistir en un centro, que es el deseo inagotable para lo bueno, alrededor de un crecimiento de materia psíquica y corporal."13 Por eso es el grito de la víctima lo que crea el lazo de comunidad, porque "a fondo del corazón de todo ser humano, de niñez más temprana hasta la tumba, hay algo que siga esperando indomablemente, en los dientes de toda experiencia de crímenes cometidos, sufridos y vistos, que el bien y no el mal se le hará." ${ }^{++} \mathrm{La}$ solidaridad no es un arreglo de intereses:

Para Weil, [la justicia] es algo más radical. Simplemente no tengo en la realidad intereses independientemente definibles de este tipo: si pienso que sí, he distorsionado totalmente el carácter esencial de la virtud en las interacciones humanas, y tal ver he malentendido la naturaleza del entendimiento mismo. I a justicia es lo que ocurre cuando surge una situación en que la atención mutua no calificada se cambia entre personas... El "interés" único que puedo tener...puede ser descubierto en atención a la realidad de los demás, a la perspectiva al mundo que ellos en su distancia de mí poseen. No es asunto de negociar condiciones, sino de una abandono universal de la idea de derechos sobre los cuales se fundamenta la práctica de la negociación. ${ }^{15}$ 
Entonces ¿cuál es la tarea filosófica aquí? Lo que pienso ofrecer es más esbozo y exhortación que programa. Goizueta comenta:

"Sólo si es posible hacer reclamos normativos acerca del bien común, son posibles la justicia y la comunidad. La posibilidad de preferir algunos puntos de vista sobre otros no es una amenaza contra el pluralismo, sino su precondición. La opción preferencial por los pobres-tanto en su dimensión social, como su intelectual-es precondición para alcanzar el bien común". 16

La realidad del mundo es el estándar normativo, y esa realidad es la de la pobreza, la enfermedad, la explotación económica, el hambre y la opresión política para la mayoría. En realidad, como señala Dean Brackley, el punto de vista de las clases medias con respecto a la realidad ha sido posible solamente desde hace doscientos años. Sin embargo, trabajamos bajo "la ilusión común de ser el centro de gravedad del universo". Como resultado, "por separar a quienes no son pobres de la amenaza cotidiana de la muerte, los beneficios de la modernidad nos han inducido a un tipo de confusión crónica de bajo nivel sobre lo que es realmente importante en la vida, es decir la vida misma y el amor. Peor aún, nuestra tecnología superior y los medios de comunicación nos inducen a pensar de nuestra cultura y perspectiva en la vida como la norma, básicamente siguiendo la pista." ${ }^{7}$ Como resultado de ello, no se escucha la voz de la víctima.

Ignacio Ellacuría dijo que la tarea de la filosofía es la de desideologizar nuestro punto de vista mundial, ${ }^{18}$ y con esto quería prevenir la globalización de puntos de vista que disfrazan y distorsionan la realidad de la experiencia humana. Para cumplir con esta tarea, el filósofo debería practicar lo que Brackley denomina la "higiene cognitiva," que involucra el superar el "prejuicio original" de dividir al mundo entre gente importante y gente que no lo es. Según este autor, "La opción práctica por los pobres, la atención a la realidad sufrida, el entender la realidad y el juicio sano acerca de la realidad, sacude nuestra vista mundial en sus fundamentos. Ayuda a reformar las asunciones antropológicas, cosmológicas y cognitivas básicas que forman el horizonte para nuestra interpretación." Y continúa observando que "la víctima está en el corazón del modelo cognitivo, y el modelo confirme que la víctima está en el corazón de la realidad."19 
La tentación será siempre imponer el silencio sobre las víctimas de la historia e ignorarlas, diciendo simplemente que habrá siempre ganadores y perdedores. Nuestra relación con ellos puede ser externalizada, de modo que involucre solamente una contribución económica, de modo que no compromete ni la persona ni la expectativa de la vida de uno. Pero de hecho, la externalización de la relación con las víctimas, los pobres y los marginalizados, consiste a la misma vez en deshumanizarlos. Es de aceptar la opción de Rorty de excluir las víctimas del "nosotros." De otro modo, para ser partidario de las víctimas, y modelar al mundo desde la perspectiva de la realidad que cada día los oprime, es de transformar tanto a las víctimas como a nosotros mismos. Peter-Hans Kolvenbach, S.J., Superior General de los jesuitas, dice que la opción por los pobres resulta en su humanización y personalización. Afirma: "este resultado no es una meta externa sino el término al que tiende la dinámica de la opción. Porque la opción por los pobres es ante todo una relación, una alian$\mathrm{za}$, un jugarse con ellos la suerte." Y continúa: "sin embargo, sólo esa relación vital salva al pobre y a quien la entabla. Al pobre lo salva de su minusvalía y el que opta es liberado de su alienación. Lo que salva es la trascendencia que implica la relación: salir de sí y llegar respetuosamente al otro...."

No debemos engañarnos pensando que esta higiene cognitiva es fácil. Hay un tipo de escala por los cuales pasa la gente: 1) el horror: "Dios mío, no sabía que fuera tan malo"; 2) la determinación: "Vamos a repararlo"; 3) la desesperación: "No podemos repararlo. Vamos a olvidarlo"; 4) la solidaridad: "esos" sustituido por "nosotros," "ese pueblo" por "mi pueblo." La posibilidad de llegar al nivel 4 es el desafío verdadero, especialmente para filósofos del Primer Mundo. Implica en primer lugar, que nosotros mismos debemos luchar para alcanzar a la solidaridad, y que cada uno deberá buscar su propio camino. Sócrates pagó con su vida para su compromiso, como también lo hizo Ellacuría. Pero la tarea es sin embargo indispensable. Ellacuría nos habla de la siguiente manera:

Es cierto que nuestros pueblos necesitan de transformación, pero de una transformación llena de verdad; de lo contrario, no vamos a la liberación del hombre sino a su alienación. La filosofía como búsqueda de la plenitud de la verdad, esto es, no a la manera de ausencia de error, sino de la presencia plena de la realidad, es así un 
elemento indispensable en la liberación integral de nuestros pueblos. Cuando estos pueblos cuenten con la posibilidad real de pensar por sí mismos en todos los órdenes del pensamiento, es que ya van camino de la libertad y de la posesión plena de sí mismos. He ahí el para qué de la filosofía."

La "presencia plena de la realidad" a que Ellacuría hace referencia es la realidad de la mayoría pobre. Es una paradoja de la no participación que la carencia del acceso a la conversación hace imposible el escapar la victimización. Para los filósofos, ser partidarios de las víctimas es darles una voz en la conversación; así, en las palabras poderosas de Monseñor Romero, pueden ser "la voz de los sin voz." Pero sin la solidaridad, tal gesto carece de la autenticidad. La victimización significa la falta de control, y el control no puede simplemente ser otorgado como favor. Hay que asirlo.

La mayoría de los filósofos son academicos, lo que significa que estamos comprometidos en enseñar lo que sabemos. La solidaridad, con todo, involucra el permitir que nosotros mismos participaremos en un proceso de aprender también, que tenemos que ser instruidos por los pobres sobre la realidad de su situación. La solidaridad con los pobres implica necesariamente, por eso, una transformación de las universidades donde enseñamos. Implica también la superación del aislamiento que demasiadas veces caracteriza nuestra relación con la cultura más allá de nuestra profesión. He aquí Brackley:

"A menos que la educación se dirija a la manera en que está fundado nuestro pensamiento en nuestros compromisos y apoyado por las estructuras de nuestra afectividad, entonces, lo que sea nuestra racionalidad, la manera de que buscamos la verdad debe ser disputada por razones estrictamente académicas... No podemos entender el significado de la vida por analizarlo desde lejos..., menos aun por separar quirúrgicamente los hechos de los valores. El entender el drama irreduciblemente moral de la vida exige la simpatía moral y el compromiso práctico"..2

El rigor académico significa un compromiso a buscar la verdad de la realidad de nuestro mundo. La realidad es el estándar con lo cual juzgamos el éxito de la búsqueda.

Quisiera terminar esta conferencia con un desafío poderoso que propone Dean Brackley. "El punto es," dice, “ir más allá de la idea 
tradicional que el saber es observar, a la exclusión del compromiso." Continúa:

"Esta amplia estructura para la educación dice: no ves claramente si no amas a los demás y te comprometes a ellos. Dentro de esta estructura, el estudio formal en la tradición occidental cobra sentido. Dentro de esta estructura, partir de una opción desequilibrada por los pobres frente a un mundo desequilibrado, el discurso comparte algo del tono desequilibrado de los profetas hebreos y suena menos griego y menos calificado. Denuncia y anuncia."

...La pregunta sería si es permitido no tener las cuestiones de la justicia como enfoque primario del estudio y investigación. A la universidad que no bloque la marcha de la injusticia social se le acusará como cómplice de ésta. ${ }^{23}$

Haciendo referencia de nuevo a las palabras de Tarrou: "Por esto decido ponerme del lado de las víctimas para evitar estragos." El hecho de ser partidario de las víctimas en una sociedad empapada con el consumismo exige al menos tanta atención como la atención encomendada por el doctor Tarrou en la ciudad afligida por la plaga. El éxito o el fracaso del esfuerzo determinará nuestra contribución a la construcción de una comunidad humana que incluye a toda la humanidad.

\section{NOTAS}

1. Albert Camus, La Peste, trad.: Rosa Chacel (Buenos Aires: Editorial Sudamericana, 1998), 198-99.

2. "The Common Good and the Marginalized," Conversations on Jesuit Higher Education, no. 13 (Spring 1998), 23.

3. Ibid.

4. Henry Shuc, Basic Rights, 2nd ed. (Princeton: Princeton University Press, 1996), 41-42.

5. Dean Brackley, SJ, "Higher Standards for Higher Education: The Christian University and Solidarity," <http://www.crcighton.edu/CollaborativeMinistry/ brackley.html>.

Muchos temas de este artículo deben su génesis a la influencia de Brackley. Mi dcuda con él es cnormc.

6. Robert Nozick, Anarquia, estado y utopia, trad. Rolando Tamayo (México: Fondo de cultura cconómica, 1988), cap. 7.

7. "Utopía y profetismo," en Mysterium Liberationis: Conceptos fundamentales de la teología de la liberación, tomo I, I. Ellacuría, SJ, y J. Sobrino, SJ (cds.) (Madrid: Editorial Trotta, 1990). 
8. "Fundamentos Filosóficos de una 'Civilización de la Pobreza'," Estudios Centroamericanos, no. 583 (mayo 1997).

9. Richard Rorty, "Moral Universalism and Economic Triage." hetp:// www.unesco.org/phiweb/uk/2rpu/rort/rort.heml.

10. Ibid.

11. Citado en Martha Nussbaum, "Non-Relative Virtues: An Aristotelian Approach," Midwest Studies in Philosophy, vol. XIII, ed. P. A. French, T. E. Uehling, Jr., and H. K. Wettstein (Notre Dame, IN: University of Notre Dame Press, 1988), 32.

12. "Compassion: The Core of Spiritual Leadership," Worship, 51(1977), 13.

13. Citado en Steven Burns, "Justice and Impersonality: Simone Weil on Rights and Obligations," Laval Théologique et Philosophique 49(1993), 486.

14. Ibid., 480.

15. Rowan Williams, "Critical Notice: Simone Weil, by Peter Winch," Philosophical Investigations 14(1991), 156.

16. "The Common Good and the Marginalized," 24.

17. Brackley, "Higher Standards."

18. "Filosofía, ¿para qué?" $A B R A$, no. 11 (1976), pp. $42-48$

19. Brackley, "Higher Standards."

20. "La Opción por los Pobres ante el Reto de la Superación de la Pobreza," SIC Venezuela no. 602 (marzo 1998).

21. "Filosofía, ¿para qué?", Op. cit., p. 48.

22. "Higher Standards," énfasis en el original.

23. "The Christian University and Liberation: The Challenge of the UCA," Discovery: Jesuit International Ministries, no. 2 (Dec. 1992), 11-12. 